\title{
Anti-factor VIII Antibodies (Inhibitors) in Hemophilia A: In Dire Need of Basic and Therapeutic Research
}

\author{
Srini V. Kaveri
}

Published online: 20 January 2009

(C) Humana Press Inc. 2009

Hemophilia A, a congenital, severe bleeding disorder, is caused by the absence or functional abnormality of factor VIII (FVIII) that occurs with a frequency of about one in 5,000 boys. FVIII is produced in the liver, and minute amounts of which $(0.2 \mu \mathrm{g} / \mathrm{ml}$ plasma) ensure an efficient coagulation. Abnormalities in the gene encoding FVIII lead to the deficiency of FVIII or production of a functionally defective molecule. Therefore, substituting the FVIII molecule represents the treatment of choice during bleeding incidences in hemophilia patients. Thus, most hemophilia patients require regular supplementation with intravenously administered recombinant or plasma-derived FVIII. About $25-40 \%$ of the hemophilia A patients who receive FVIII develop antibodies against the infused FVIII. These antiFVIII alloantibodies are called "inhibitors."

FVIII inhibitors neutralize the infused FVIII, thus exposing the patients to an extremely precarious situation and a serious challenge to the clinicians, as subsequent

S. V. Kaveri

Centre de Recherche des Cordeliers,

Université Pierre et Marie Curie - Paris6, UMR S 872,

Paris 75006, France

S. V. Kaveri

Université Paris Descartes, UMR S 872,

Paris 75006, France

S. V. Kaveri

INSERM, U872,

Paris 75006, France

S. V. Kaveri $(\bowtie)$

INSERM UMR S 872 Equipe 16 -

Centre de Recherche des Cordeliers,

15 rue de l'école de médecine,

Paris 75006, France

e-mail: Srini.Kaveri@crc.jussieu.fr treatment options become extremely limited. Immune tolerance induction is the currently practiced approach to eradicate inhibitors, to restore replacement FVIII pharmacokinetics, and to improve bleeding management and thereby the quality of life. However, the exorbitant cost involved in this therapy has a direct bearing on the socioeconomic issues. With the emergence of the state-ofthe-art methods for elimination of contaminants and rapidly improving production processes that have ensured the safety of the products and the absence of contamination with blood-borne agents such as HIV, hepatitis, and prions, the risk of developing FVIII inhibitors poses a major and almost the only most serious complication in the treatment of hemophilia A patients. FVIII inhibitors have therefore been subject to extensive investigation by several groups of researchers over the last two decades. Although the basic characteristics and the mode of action of inhibitors have been well documented, issues on the nature of risk factors that predispose a patient for the development of inhibitors have remained a subject of debate. Designing appropriate therapeutic strategies to prevent the emergence and to eradicate the anti-FVIII antibodies is the most important concern. A thorough knowledge on the predisposing factors and a careful dissection of both cellular and molecular events leading to the development of inhibitors are important prerequisites in the conception of preventive and therapeutic measures. With this perspective, in this issue of Clinical Reviews in Allergy and Immunology, we have gathered the current views from experts who have contributed significantly on various aspects of FVIII inhibitor development. The authors provide an in depth assessment of diverse topics ranging from risk factors that predispose the hemophilia patients for the development of inhibitors to the conception of novel immunointervention strategies to combat the occurrence of FVIII inhibitors. 
Ghosh and Shetty open the discussion on the risk factors: patient-related genetic and nongenetic and also treatmentrelated risk factors including FVIII gene mutation type, ethnicity, family history of inhibitors, HLA haplotype, polymorphisms in the immune response genes, and the type and purity of coagulation factor concentrates used for treatment, age at the time of first exposure, initial doses of concentrate, mode of infusion, surgery, frequency of treatment prior to inhibitor development, and intensity of treatment or regular prophylaxis.

One of the means by which FVIII inhibitors neutralize the function of FVIII is through steric hindrance of the interaction of FVIII with a number of cofactors and molecules of the coagulation, which are critical for an efficient completion of the cascade. In this respect, it is important to identify precisely the epitopes recognized by anti-FVIII antibodies. Epitope mapping of inhibitors has been the subject of intense research. Two leaders in the area have summarized the current literature and their observations on epitope mapping: Lavigne-Lissalde and her colleagues have presented the most recent findings on the isotypes, kinetic properties, and mechanism of action of anti-FVIII Abs [1]. The authors also describe a novel approach that is likely to facilitate the monitoring of changes in the epitope specificity FVIII inhibitors.

Detailed characterization of these B cell epitopes will allow us to understand the importance of immunologically critical surfaces on the FVIII molecule. The generation of inhibitory antibodies by $\mathrm{B}$ cells requires signaling from $\mathrm{T}$ lymphocytes that recognize FVIII-derived peptides when antigen-presenting cells present these peptides in the context of HLA class II molecules. A stable association of peptide sequences of FVIII with HLA is a prerequisite for the activation of $\mathrm{T}$ cells [2]. These peptide sequences are termed "T-cell epitopes." Pratt and Thompson discuss on how characterization of MHC Class II tetramers that bind FVIII-derived peptides is providing useful information in the understanding of T-cell responses to FVIII.

In addition to steric hindrance, anti-FVIII antibodies neutralize FVIII through an interesting mechanism involving active direct proteolytic hydrolysis of FVIII. Alloantibodies from a significant number of patients possess hydrolytic capacity. The molecular pattern of cleavage of FVIII and the kinetics of hydrolysis have been thoroughly investigated [3-5]. However, several interesting issues concerning the origin of catalytic antibodies and their role in the evolution of the pathological processes have remained elusive. Wootla and colleagues provide several plausible hypotheses to explain the emergence and role of catalytic antibodies. Indeed, the emergence of not only catalytic antibodies but that of inhibitors as such is not well understood.
A rupture in immune tolerance towards FVIII due to the absence of FVIII during the fetal life cannot fully explain the immunogenicity of FVIII in hemophilia A patients since all the patients do not mount an immune response against the injected FVIII, thus opening an intense debate on a number of questions pertaining to the immunological events starting from the first encounter of the antigen FVIII, culminating in the generation of anti-FVIII antibodies by $\mathrm{B}$ lymphocytes. These interesting issues are reviewed by André and his colleagues. Similarly, understanding the factors that dictate the formation of inhibitors and how they can be controlled is vital to designing strategies to intervene in the initiation of the immune response or an ongoing immune reaction [6,7]. Scott and his colleagues provide an overview of the research aimed at modulating the immune response against FVIII.

Intense investigation over the last two decades has helped the identification of risk factors, understanding molecular mechanisms of the mechanisms of neutralizing action of FVIII inhibitors and in providing pointers towards novel therapeutic strategies. However, several issues regarding clinical and regulatory guidelines have remained open. These questions have been addressed by Tellier and her colleagues and should have repercussions at the scientific and medical levels and, thus, are of societal relevance.

We believe that the contents of this issue provide an update on the research activities in the area of FVIII inhibitors and stimulate further research towards the conception of immunotherapeutic strategies to treat patients with FVIII inhibitors. One central theme that we have not directly addressed is the loss of tolerance and the mechanisms associated with it. For this, we refer the reader to several recent publications that deal with this concept, including the genetic basis and the role of $\mathrm{T}$ regulatory cells in both systemic and organ-specific disease [8-25].

\section{References}

1. Lavigne-Lissalde G, Tarrade C, Lapalud P et al (2008) Simultaneous detection and epitope mapping of anti-factor VIII antibodies. Thromb Haemost 99:1090-1096

2. James EA, Kwok WW, Ettinger RA, Thompson AR, Pratt KP (2007) T-cell responses over time in a mild hemophilia A inhibitor subject: epitope identification and transient immunogenicity of the corresponding self-peptide. J Thromb Haemost 5:2399-2407

3. Lacroix-Desmazes S, Bayry J, Misra N et al (2002) The prevalence of proteolytic antibodies against factor VIII in hemophilia A. N Engl J Med 346:662-667

4. Lacroix-Desmazes S, Moreau A, Sooryanarayana et al (1999) Catalytic activity of anti-factor VIII antibodies (FVIII inhibitors) in patients with hemophilia A. Nature Med 5:1044-1047

5. Lacroix-Desmazes S, Wootla B, Dasgupta S et al (2006) Catalytic IgG from patients with hemophilia A inactivate therapeutic factor VIII. J Immunol 177:1355-1363 
6. Lacroix-Desmazes S, Navarrete AM, Andre S, Bayry J, Kaveri SV, Dasgupta S (2008) Dynamics of factor VIII interactions determine its immunologic fate in hemophilia A. Blood 112:240 249

7. Dasgupta S, Bayry J, Andre S, Dimitrov JD, Kaveri SV, LacroixDesmazes S (2008) Auditing protein therapeutics management by professional APCs: toward prevention of immune responses against therapeutic proteins. J Immunol 181:1609-1615

8. Baker RL, Wagner DH Jr, Haskins K (2008) CD40 on NOD CD4 $\mathrm{T}$ cells contributes to their activation and pathogenicity. J Autoimmun 31:385-392

9. Culton DA, Qian Y, Li N et al (2008) Advances in pemphigus and its endemic pemphigus foliaceus (Fogo Salvagem) phenotype: a paradigm of human autoimmunity. J Autoimmun 31:311-324

10. Shoenfeld Y, Selmi C, Zimlichman E et al (2008) The autoimmunologist: geoepidemiology, a new center of gravity, and prime time for autoimmunity. J Autoimmun 31:325-330

11. Kerr EC, Raveney BJ, Copland DA et al (2008) Analysis of retinal cellular infiltrate in experimental autoimmune uveoretinitis reveals multiple regulatory cell populations. J Autoimmmun $31: 354-361$

12. Marino E, Grey ST (2008) A new role for an old player: do B cells unleash the self-reactive CD8+ T cell storm necessary for the development of type 1 diabetes? J Autoimmun 31:301-305

13. Schulze C, Munoz LE, Franz S et al (2008) Clearance deficiencya potential link between infections and autoimmunity. Autoimmun Rev 8:5-8

14. La Cava A (2008) Tregs are regulated by cytokines: implications for autoimmunity. Autoimmun Rev 8:83-87
15. Jenks SA, Sanz I (2009) Altered B cell receptor signaling in human systemic lupus erythematosus. Autoimmun Rev (in press)

16. Pisetsky DS (2008) The role of innate immunity in the induction of autoimmunity. Autoimmun Rev 8:69-72

17. Morahan G, Peeva V, Mehta M et al (2008) Systems genetics can provide new insights to immune regulation and autoimmunity. $\mathrm{J}$ Autoimmun 31:233-236

18. Hogan TV, Ang DK, Gleeson PA et al (2008) Extrathymic mechanisms of $\mathrm{T}$ cell tolerance: Lessons from autoimmune gastritis. J Autoimmun 31:268-273

19. Lan RY, Mackay IR, Gershwin ME (2007) Regulatory T cells in the prevention of mucosal inflammatory diseases: patrolling the border. J Autoimmun 29:272-280

20. Peng Y, Martin DA, Kenkel J et al (2007) Innate and adaptive immune response to apoptotic cells. J Autoimmun 29:303-309

21. Ryan KR, Patel SD, Stephens LA et al (2007) Death, adaptation and regulation: the three pillars of immune tolerance restrict the risk of autoimmune disease caused by molecular mimicry. J Autoimmun 29:262-271

22. Pasquali JL, Soulas-Sprauel P, Korganow AS et al (2007) Autoreactive B cells in transgenic mice. J Autoimmun 29:250-256

23. Crispin JC, Alcocer-Varela J (2007) The role myeloid dendritic cells play in the pathogenesis of systemic lupus erythematosus. Autoimmun Rev 6:450-456

24. Abbas AK, Lohr J, Knoechel B (2007) Balancing autoaggressive and protective T cell responses. J Autoimmun 28:59-61

25. Kristof K, Erdei A, Bajtay Z (2008) Set a thief to catch a thief: self-reactive innate lymphocytes and self tolerance. Autoimmun Rev 7:278-283 